This is the author's final, peer-reviewed manuscript as accepted for publication. The publisher-formatted version may be available through the publisher's web site or your institution's library.

\title{
When caregivers are in need of care: African American caregivers' preferences for their own later life care
}

Jared R. Anderson, William L. Turner

\section{How to cite this manuscript}

If you make reference to this version of the manuscript, use the following information:

Anderson, J. R., \& Turner, W. L. (2010). When caregivers are in need of care: African American caregivers' preferences for their own later life care. Retrieved from http://krex.ksu.edu

\section{Published Version Information}

Citation: Anderson, J. R., \& Turner, W. L. (2010). When caregivers are in need of care: African American caregivers' preferences for their own later life care. Journal of Aging Studies, 24(1), 65-73.

Copyright: ( 2009 Elsevier Inc.

Digital Object Identifier (DOI): doi:10.1016/j.jaging.2008.06.002

Publisher's Link: http://www.sciencedirect.com/science/article/pii/S0890406509000401

This item was retrieved from the K-State Research Exchange (K-REx), the institutional repository of Kansas State University. K-REx is available at http://krex.ksu.edu 
Running head: WHEN CAREGIVERS ARE IN NEED OF CARE: AFRICAN AMERICAN

When Caregivers are in Need of Care: African American Caregivers’ Preferences for Their Own Later Life Care

Jared R. Anderson

Kansas State University

William L. Turner

University of Minnesota

Address correspondence to: Jared R. Anderson, School of Family Studies and Human Services, Kansas State University, 209 Campus Creek Complex, Manhattan, KS 66506 (jra@ksu.edu) 785-532-4198 (Phone); 785-532-6523 (Fax) 
When Caregivers are in Need of Care: African American Caregivers’ Preferences for Their Own Later Life Care

\begin{abstract}
To “care for one’s own” is a cultural expectation within a larger ethic of care in the African American community. Applied to caregiving of aging elders, this ethic of care emphasizes the importance of providing in-home family care rather than opting for out of home placement. This study explores why a subset of African American caregivers prefer or are open to out of home placement over in-home family care if they are no longer able to care for themselves. In-depth interviews with 24 family caregivers are analyzed. Three themes emerged including the desire to “spare our children” the burden associated with caregiving, viewing the next generation of potential caregivers as not equipped for the task, and having no one left to provide care for them.
\end{abstract}

Keywords: Later Life Care, African American Caregivers, Decision Making 
Caregiving decisions for family members who are no longer able to independently care for themselves are often some of the most difficult and agonizing that individuals and families can make. Historically, immediate and extended family were the sole providers of elder care, as there were few, if any, alternatives such as formal or institutional care (Hill, 1997). Over the last half of the twentieth century, as institutional care settings began to grow and as demographic patterns began to change, such as smaller family size, greater geographic dispersion among family members, and an increase in life expectancy, the rate of institutionalization among aging African Americans began to rise (Groger \& Mayberry, 2001). Despite this increase in the rate of institutionalization, the expectation of filial obligation (i.e. in-home family care) and negative attitudes toward institutional care remains strong, setting up a rising divide between what may be ideal and what is realistic given life circumstances (Groger \& Mayberry, 2001). Within this context of increased options and continued strong expectations for in-home family care for aging elders, the present study explores why a subset of African American caregivers state that they would prefer or are open to out of home placement over in-home family care if they are no longer able to take care of themselves.

\section{Ethic of Care}

The term “ethic of care” developed out of the Gilligan’s (1982) theorizing on the moral development of women. In her model, women’s morality centers on notions of caring and responsibility rather than rights and rules. In this ethic of care model, the highest moral imperative requires taking care of needs and sustaining relationships. This early work has continued to be developed and refined (Brabeck, 1989; Skoe, 1998; Tronto, 2001) and applied to areas as diverse as nursing (Dyson, 1997) and economics (Taylor, 1998). It is theorized that this 
ethic of care develops from an individual's feeling of interconnectedness with others and that it is contextual and arises from experience.

Robert Hill (1972), in his seminal work on African American families, noted that strong kinship bonds, a strong work orientation, adaptability of family roles, a strong achievement orientation, and a strong religious orientation were "characteristics that have been functional for their [African American families] survival, development and stability” (p. 4). In the twenty-five year revision and update of his earlier work, Hill (1999) noted that strong kinship bonds were the most enduring family strength and were rooted in West African cultural values. This strong kinship bond includes the importance of the extended family network, the inclusion of fictive kin as family, the high value placed on children, and honor and respect for elders (Billingsley, 1992; McAdoo, 1998). According to Shirley Hill (1997), the cultural valuing of extended family ties, respect for elders, valuing children, and a strong religious orientation together create an ethic of caring in African American families (p. 111).

This ethic of care applied to the care of aging elders emphasizes the importance of providing in-home care to family and kin rather than opting for paid in-home services or out of home placement. The West African legacy of strong kinship bonds coupled with the sociohistorical factors that have shaped the lives of African Americans in the United States has greatly influenced the late-life caregiving decision-making process for many African Americans. Most health care settings, including most nursing homes and other elder care facilities, were not accessible to African Americans until recently. Many African Americans who are eligible and currently candidates for nursing home care are the same people who experienced overt hostility and discrimination from many of the institutions that are now offering supportive care (Smith, 1991). This transformation is often viewed with skepticism and wariness, and therefore, the 
establishment medical care facilities, including nursing homes, continue to be viewed with a sense of mistrust (Waters, 2001). These experiences coupled with traditional cultural values that have placed the family, especially children and elders, at the center of care has resulted in the cultural precept to “care for your own” (Wimberly, 1997). This ethic of care and the precept to “care for your own” is often invoked to explain the historical underutilization of nursing home

services by African Americans (Greene \& Ondrich, 1990; Steinbach, 1992; Wolinsky, Callahan, Fitzgerald, \& Johnson, 1992) and the continued gap in the use of hospice services (Crawley, Payne, Bolden, Payne, Washington, \& Williams, 2000).

Recent demographic changes across all ethnic groups in the United States have the potential to influence families and their ability to provide traditional in-home care. These changes in families include: decreased family size, increased access to and levels of education, greater concentration in urban versus rural areas, increased life expectancy and greater geographical dispersion of families as they become more mobile in seeking and following job opportunities (Groger \& Mayberry, 2001; Zarit \& Eggebeen, 1995). As families in general are smaller and more dispersed geographically and as the older adult population continues to rise, African American elders now make up the fastest growing segment of the African American population (Wykle \& Kaskel, 1991), the ability to follow the ethic to care for one's own by providing in-home care has become more challenging (Bryant \& Rakowski, 1992; DilworthAnderson, 1992).

\section{Attitudes toward Nursing Home Placement}

Nursing home placement is most often viewed as a last resort, to be considered when all other options have been exhausted. In general, many African Americans tend to hold negative views about nursing homes and often report an unwillingness to place a family member into a 
home or to be placed themselves (Groger \& Mayberry 2001; Schoenberg \& Coward, 1997;

Sudha \& Mutran, 1999). Sudha and Mutran (1999), found that African American caregivers in their sample generally held negative attitudes toward nursing homes. But, caregivers with greater education, those who were younger or male, those who experienced greater caregiver stress and burden, and those with fewer siblings were more open to placing elders in a nursing home. In addition, Groger and Mayberry (2001), in their exploration of African Americans' ideas about filial obligation, found that although the ethic of care was strong across all the participants they interviewed, the fixed support for in-home care was dependent on the age and the caregiving experience of the interviewee. While all participants considered nursing home placement to be objectionable, the younger the participants, the more adamant they were that nursing home placement was avoiding one’s moral duty and responsibility. Middle age participants, many of whom were caregivers themselves, believed nursing home placement to be a last resort after other measures were exhausted. In contrast, elders spoke more about the importance of being visited and made to feel loved and not forgotten rather than holding to a value that they be cared for in the home of a family member. These findings were similar to what Brody and colleagues $(1983,1984)$ found in their study of three generations of women in Philadelphia. All three generations of women believed in the importance of filial responsibility and giving affective support. They differed in their expectations for providing day-to-day and instrumental care with the youngest generation of women the most likely to espouse an expectation of such care and the oldest generation the least.

\section{Caregiver Burden}

For caregivers, the decision to provide care often means a reorganization of priorities, lifestyle, and time. Although caregiving can be, and often is rewarding (Kramer, 1997), it can 
also come with physical and emotional costs to the caregiver. Research in this area is not definitive, but, in general, providing in-home care for a frail or demented elder results in increased levels of stress and depression, and decreased levels of subjective well-being, physical health, and self-efficacy (Pinquart \& Sorensen, 2003). In addition, research shows that increased caregiver burden is associated with a greater openness to exploring alternative caregiving options. The greater the perceived burden, the more likely the caregiver is to believe that out of home placement is an acceptable option (McFall \& Miller, 1992; Young, Kosloski, \& Montgomery, 1998).

\section{Method}

The current study is part of a larger study examining caregiving in the African American community. The purpose of the original study was to understand how families organized themselves in support of an aging family member and the process families went through in order to make care decisions for aging elders. The original study consisted of individual interviews with 50 family caregivers and eight caregiver focus groups for a total of 88 caregivers. Criteria for study participation included currently serving as a caregiver for an adult family member or previously serving as a caregiver for an adult family member who had died within the last decade. Participants were self-defined caregivers, as the definition of the term "caregiver" was not defined a priori. See Turner, Wallace, Anderson, and Bird (2004) for a detailed description of the purpose and procedures of the larger study.

Participants in the Study

Participants for this study were selected from the original group of caregivers by their response to the open-ended question, If something were to happen to you, so that you were no longer able to care for yourself, who would take care of you? Twenty-four adult caregivers 
responded that they preferred or were open/resigned to out of home, non-family care placements (e.g., nursing home care, assisted living facilities, or personal care homes) for their own later life care. This group of caregivers ranged in age from 36 to 79 , were predominantly female $(n=22)$, and represented diverse educational, socioeconomic, and geographical backgrounds. Caregivers’ educational attainment ranged from less than a high school education to obtaining advanced graduate or professional degrees. Income for this sub-group of caregivers ranged from less than $\$ 10,000$ per year to greater than $\$ 100,000$ and caregivers represented states from the Northeast (New York), Southeast (Georgia, North Carolina), and the Midwest (Minnesota, Illinois). The vast majority of care receivers were older adults (70 years old or older, age range 52-98) and 12 out of the 24 care receivers were currently residing in out of home, formal care facilities (e.g., nursing homes or personal care homes).

According to the caregiver typology developed by Dilworth-Anderson, Williams, and Cooper (1999), nine participants could be characterized as primary caregivers, four as secondary caregivers, five as tertiary caregivers, and six participants did not fit the proposed typology. Caregiver types can be distinguished by the caregiver's level of responsibility for the person's care and the type of tasks engaged in by the caregiver. Primary caregivers provided care either alone or with the assistance of someone else but were the major decision makers with the greatest responsibility for day-to-day care. Secondary caregivers were often involved in day-today care, often rivaling the levels of primary caregivers, but they were not the primary decision makers. They provided care under the direction of the primary caregiver and therefore had less overall responsibility. Tertiary caregivers were less involved in day-to-day care, often providing more “specialized tasks such as grocery shopping, yard work, or paying bills” (DilworthAnderson et al., 1999). They did their work under the direction of the primary caregivers and had 
little direct decision-making responsibility. The six participants who did not fit the typology proposed by Dilworth-Anderson et al., were primary decision makers but were not involved in direct day-to-day caregiving tasks. In these cases, the caregivers had general decision making authority and used that authority in placing their family member into formal care (for example, nursing home, personal care home).

Procedure

Members of the research team had contacts with churches and community centers at each regional study site. These church and community contacts assisted with the recruitment of participants by posting flyers describing the study and by alerting their friends or congregants of the study. Individuals who were interested in participating in the study then contacted the research team. The purpose of the study and the research process were described, and if interested, an interview date was scheduled. Interviews were conducted in the participant's home, were audiotaped, and generally lasted between one and two hours. All of the interviews were conducted by the same person, an African American female doctoral student who was a marriage and family therapist and an ordained minister.

Analysis

Qualitative analyses of caregiver interviews were based on data reduction, a process that included identifying parts of the transcript that dealt with caregivers' desired future for their own later life care and identifying patterns, categories, and themes that emerged across cases (Creswell, 1994; Lofland \& Lofland, 1995; Maxwell, 1999; Tesch, 1990). The data analysis was conducted by the first author utilizing the software program NVivo (Bazeley \& Richards, 2000; QSR International, 2002). The steps in the data analysis procedure were as follows (Maxwell, 1999; Tesch, 1990): 
1. Each interview was transcribed verbatim.

2. In order to get a sense of the whole, several interviews were read through in their entirety and initial, tentative notes about potential categories and themes were recorded.

3. A line by line reading of each interview transcript followed and the list of themes and sub-categories was expanded. Similar ideas were clustered under the same theme and sub-categories within each theme were developed, if applicable. These clustered themes were abbreviated as codes.

4. The data were revisited (each transcript was read again) and the developed codes were applied to the appropriate segments of the text.

5. Coded data for each theme and sub-category were extracted from original interview transcripts and a new document was developed that displayed all coded data together, by theme/sub-category.

6. The data were re-examined, looking for exceptions, linkages between cases, and additional themes. In addition, salient quotes were highlighted that seemed to be representative of the various themes and sub-categories to be used in the dissemination of the findings.

Through this iterative process of "taking apart” the data and seeking commonalities as well as exceptions, three general themes emerged to explain caregivers' preferences for their own future later life care.

\section{Findings}

Three main themes emerged to explain why caregivers reported preferring or being open to out of home placement over in-home family care if they were no longer able to take care of 
themselves. Caregivers reported that caregiving was difficult and required many sacrifices. They indicated they did not want to be the object of that sacrifice, and they wanted to "spare their children” the burden of disrupted lives, the sacrificing of personal aspirations, and guilt. For other caregivers, they realized either no one was waiting in the wings to care for them, or those available were not equipped to provide the care that was needed. Based on the analysis process described previously, a comparative grid was developed by caregiver type. No salient differences in responses were notable between caregiver desires for future care and caregiver type.

\section{Sparing Our Children}

Participants cited not burdening others as the main reason they wanted out of home care in the future, if needed, or were at least open to the possibility of such care. The object of their protection was most often their children, who they wanted to shield from the consequences and realities of caregiving.

\section{Sparing our children from disrupted lives and livelihoods}

The foremost reason cited by caregivers for not wanting in-home family care was that they did not want to disrupt their children's current lives or livelihoods. This included not wanting their children to have to sacrifice personal aspirations and possibly their careers or to have their caregiving duties negatively influence career outcomes and productivity. Being a burden meant not only “disrupting their [children’s] lives” [Mabel] but also having the potential to interfere with work or family duties because of the strain of caregiving. Rose, a 54-year-old caregiver from the Southeast shared her concern about the ramifications that could result for her son if he was responsible for her care:

What if my son has a problem or decision to make at work and it's pressing down on him and is whether the company is going to succeed or not. I'm just giving you an example, they're big deals.... and the decision is resting on his shoulders. And he's got to come up and I'm getting on his nerves. And as a result, he makes the wrong decision, and there is 
something he missed that he should have seen, but he didn't think of it because he was preoccupied with me. How would I feel?

Her anticipatory worry about a possible future scenario is made more real by her own experience of having to drop everything and deal with her mother as her mother's illness progressed. Rose, like Mabel, does not want to interfere with her son’s success by having him “worry" and "fuss” over her, thus possibly jeopardizing his position at work.

For others, the very real experience of being a caregiver for their own family members, and the resulting limitations on their lives, created for them a commitment that they did not want to be the reason for others to experience life limitations. James, a 52-year-old caregiver from the Midwest, stated that he had been passed over for promotions over the years because he was not able to put in the hours of work that were expected because of his caregiving responsibilities at home. He also spoke of not being able to engage in common professional development activities in his field, such as attending annual conferences, because of the level of care that his wife needed and the expense that it would have been to bring in alternative care for an extended weekend. As a result, he stated that he preferred nursing home care if it came to that, so as not to disrupt the lives of his children. Mary, a 79-year-old caregiver from the Southeast, has been the caregiver of her only living sister. Although she has paid for homecare assistants to help her sister with duties such as cooking and cleaning, Mary has "put her life on hold” so that she can be there for her sister. According to Mary, these responsibilities have affected her own desires for her future care.

What would happen is I would go to a facility. My son tells me no, he is going to take care of me, but I wouldn't do that to nobody. I don't want nobody to take care of me. I won't...deprive nobody of their lives. 'Cause see, I've been deprived of mine so much, so I wouldn’t want that to happen to anyone. 
Her deprivation was not being able to participate more fully in her faith community by going to regular services, not being able to travel with the choir, and for now, putting on hold her desire to travel. Caregivers such as Mary were quick to point out that caregiving has been rewarding in many ways and that they freely chose to serve as caregivers, but that such choices have limited their own lives. Having experienced the sacrifice, they were unwilling to be the object of the sacrifice for their own family members.

Sparing our children from the struggle of limited opportunity

For some participants, the thought of having to "pull somebody from their life" to come and take care of them would be unraveling all the sacrifice and hard work that they themselves had spent a lifetime working to create. Betty, a 69-year-old caregiver from the Southeast, spent her life sacrificing for her children so that they would have more than she was able to provide for them. Her acceptance of future out of home placement is, in part, a desire to prevent her children from losing the gains they have made as a result of her hard work and sacrifice throughout her life.

...my children got good jobs and both of them finished school and college and they can go for themselves. I don’t want to mess up nothing...

Sparing our children from the guilt associated with placement

For several of the participants, part of the burden they wished to relieve for the next generation is the burden of guilt. Participants spoke of wishing they could do more for their family members and feeling they had not done enough as caregivers. The participants who were the most adamant about not wanting to be a burden to their children and who were clear about their desire to enter an out of home care facility when they could no longer care for themselves were also those who were involved in the decision to place a family member in a formal care 
facility. For them, the sense of guilt was connected to their own sense of failure to uphold the cultural tradition of providing in-home care.

Michelle, a 57-year-old caregiver from the Southeast, placed her mother in a personal care home after her mother began wandering from the house and could no longer be left at home while Michelle went to work. Two years after her mother had died in a personal care home and four years since placement, she states:

...what was so difficult was, you know, for her trying to understand why she's staying with a stranger, you know. And, for us, always the guilt, of this feeling that, you know, we can't take care of our own mother.

Joyce was a 53-year-old caregiver from the Midwest. She had a time consuming professional career in a state far from her mother. Her two sisters also were not able to provide in-home care so they agreed, with their mother's consent, to place her in a nursing home. Joyce described her family as "kin keepers" and that her generation was the first to not continue this legacy through in-home care. At the time of the interview, her mother had been in a nursing home for two years. Joyce continued to struggle with whether they had made the right decision.

...just the very fact that we would support that [nursing home placement]....were we abandoning her? You know mom was very close to her mom and we felt very close to mom. I think we struggled with what mom thought, what the community thought, what the cousins thought. Just whether this was the best and if we were dismissing some of our responsibilities for mom. ....it kind of gets to us that mom is in this position because she did [provided in-home care] for so many, her mom and sisters and that kind of thing. Damn it, I just, you know...

Joyce grew up in the rural south where the traditional cultural values continue to be strong. This legacy of care leaves her struggling with what it means to be involved in placing her mother in a care facility, especially since "they were close.” The meaning that often emerges from the traditional ethic of care is, if I really loved her I would not have left her to be cared for by others, because "good" children take care of their parents. They do not dismiss their 
responsibilities to care for their elderly parents - especially when they have a mother who has been known for her sacrificial care. Not only did Joyce and her sisters believe they had let their mother down and reneged on their moral and family responsibility, they also carried with them the belief that the extended family and community sit in judgment of their decisions. Together, these beliefs probably underlie the frustration and anger that she felt in talking about this reality.

Like Joyce, in addition to feeling guilty for not living up to the cultural precept of "caring for one's own,” some participants in this study felt that they received criticism and contempt from individuals in their extended families or church community for some of their caregiving decisions. One participant who was looking into a personal care home for her mother was told, “black people don’t put their loved one’s in homes” [Michelle]. Comments such as “well I see you finally put your mother in a home” [Rose], and others like them questioned the participant's loyalty and love for their parent which had the effect of adding to the participant's guilt for not living up to the standard of in-home care. For many, it also led to a personal commitment to shield their own children from having to go through these experiences by choosing formal out of home placement for themselves.

No one left to care

For some participants being the last member of their generation and not having a spouse, partner, or child(ren) of their own was their reason for desiring formal out of home placement or feeling resigned to out of home placement. There was no one left to provide in-home family care. Often, these participants had cared for parents, siblings, and sometimes spouses or children but now find themselves without the familial safety net that they had provided for so many years. Rita, a 72-year-old caregiver from the Northeast, stated that she took great pride in providing for her own future by purchasing long-term care insurance, developing a will, and designating one of 
her nephews to be the executor. She believed that even though she might not be able to live out her days at home, her nieces and nephews would be "all over me” wherever she finds herself, thus maintaining her connection to her family.

\section{Available but unequipped children}

Unlike participants who had no one "waiting in the wings to offer care”, others had children who could offer the next generation of caregiving. The participants, however, believed that the next generation did not have what it took to provide care and would be available, but incapable. Denise, a 49-year-old caregiver from the Midwest, had cared for both her mother and father in the last years of their lives. In speaking of the next generation of caregivers, she offered another barrier to in-home kin care.

... it's like, you know when you look at our children (laughs), it's kind of like what my mother said to me years ago, "I know you ain't going to take care of me.” But it wasn't because she said I couldn't. She assumed I would be so busy doing my own little thing that I wouldn't... But we're looking at ours, and it's like, they can't (laughter). Its like, how do I trust you with my life? You know what I'm saying? It's like, aahhhh, I don't know, maybe I should die real quick (laughs).

Yvonne, a 50-year-old caregiver from the Northeast, offered a similar sentiment. She stated that if she were married her first choice would be for her husband to care for her at home. Because she is not currently married, has aging parents who will soon be in need of their own care, and has few other relatives in the area, Yvonne wanted to be placed in "some kind of facility.” When speaking about whether she saw her daughter as providing care, she states:

I don’t know if Towanna would be ready to do something like that, I mean she's had the life of luxury; she doesn't know anything about stuff like that.

For Yvonne, her hard work was focused on giving herself and her children a better life.

Her children have wanted for little, but in that "life of luxury", as she put it, there was a tradeoff. Ladner (1998) stated that one consequence of a childhood and adolescence "unfettered by 
serious responsibilities" is that children are not equipped to take on responsibilities such as caregiving that require self-sacrifice, delayed gratification, and altered lifestyles (p. 6). The result is the need to prepare for one's own care when independent living is no longer possible.

\section{Make your presence known}

Despite caregivers' stated preference or willingness to be placed in a formal care facility at some point in their future, participants were quick to point out that they continued to expect love and care from family members in the form of frequent visits. These visits and the attention that came with them would continue to bind the caregivers with family and would also serve to protect them against a system (for example, nursing home facilities) that was perceived to be negligible at times in the care of patients of color.

Although participants in many cases were willing to live in a formal care facility in the future, their decision was made with the assumption that their family would continue to be active in their lives and would not abandon them there. Thus, they continued to support and believe strongly in the "ethic of care." For them, however, the way in which this ethic would be carried out in their own lives had changed from "being taken care of" to "being kept in mind and attended to." When describing their comfort with formal care placement, participants would quickly add comments such as, “just don’t leave me there” (Peggy), or “don’t forget about me” (Joanne). Participants did not want to be burdensome, but they also did not want to be warehoused and forgotten. For Betty, frequent visits from family and occasional special treats would make living in a nursing home more than palatable.

What I would want now, which I know they [her family] would do it, they come to see me and they come take me out of the home....and we go over there to the motel and we stay over there and enjoy each other and go to church and rent it for the weekend. I'll just enjoy that. 
In addition to wanting their families to come visit and spend time with them, "making your presence known” was also about checking in to see that the care they were receiving was good and above board. There was a general acknowledgement that no matter how good the care facility was, it could not replicate the love and attention of family. There also was concern that lack of funding for adequate staff, poorly trained staff, or insidious racism and discrimination could work in whole or in part to jeopardize their health and well-being. The participants wanted their family members to visit not only for emotional connection and support, but also to act as the "nursing home police” to ensure their welfare. This explanation from Patrice, a 61-year-old caregiver from the Northeast, is typical of the participants.

I think that if you put your parents in [nursing home] and you don't go [visit] until his birthday or you don't go until Mother's Day or Father's Day or Christmas or Easter, because people know when those days are, so of course they're going to do what they're supposed to do and have them all shiny when you get there. But I think you need to be in and out of it all different times, different days. You don't come every Wednesday at 12:00.

Family "presence” is about belonging and connection, the desire to feel valued by being visited and having people take the time to spend with you. Being valued also means that those who love you will protect you and look after your physical, as well as emotional well-being. Though their day-to-day care was foreseen to be in the hands of strangers, they continued to expect and long for the one’s they loved to "care for them” in other ways.

\section{Discussion}

The current study explores the reasons caregivers reported preferring or being open to formal out of home care over in-home family care if they were no longer able to care for themselves. In general, caregivers believed institutional care was preferable to in-home care because they, as caregivers, knew the sacrifices that caregiving entailed and wanted to spare their children from having to make those sacrifices. In addition, for some caregivers, there was no one 
available who could take on the responsibility of care or no one they felt was up to the task. In many ways, these findings highlight possible tensions in the ethic of care in the African American community and between the ethic of in-home care and the changing social, economic, and demographic realities that make it so difficult to continue.

Ethic of Care

The valuing of extended family ties, valuing children, respect for elders and a strong religious orientation together create an ethic of caring in the African American community (Hill, 1997). The strong valuing of children can be seen in many of the reasons African American caregivers in this study gave for not wanting familial care if they are no longer able to care for themselves. Sparing children from disrupting their lives to provide care, from having to sacrifice personal aspirations related to family life or career, from limited involvement in community life or personal interests, and from the guilt that sometimes resulted from not living up to the cultural expectation of familial in-home care all highlight the caregivers' valuing of their children. In addition, many of the caregivers' were keenly aware of the sacrifices they had made in order to provide more opportunities for their children. They had experienced for themselves the insidious nature of racism that limited opportunities and upward mobility (Billingsley, 1992) and they were unwilling to add to their children’s struggle for success by placing additional responsibilities of care on them. These caregivers’ highly valued their children and their children's future. They had personally sacrificed to create many opportunities for their children that they themselves did not have and they were reluctant to see their sacrifices possibly unravel as a result of care that they might require.

Within the cultural ethic of caring in the African American community that places children and elders in the center of care, a tension can arise between the valuing of children and 
respect for elders when attempting to follow the ethic to “care for your own” (Wimberly, 1997). By not "allowing" their children to provide in-home familial care for them in the future, the caregivers' were privileging the valuing of children over caring for elders through in-home familial care - at least in their lives and when they were the object of care. The willing selfsacrifice, but unwillingness to be the object of someone else's sacrifice is consistent with what Romero (2000) calls the Icon of the Strong Black Woman. According to Romero, many African American women grow up with and embrace an image of self that outwardly exudes strength and is characterized by self-sacrifice and often taking on more than she can realistically handle. Given the historical and continued discrimination and inequities that African Americans experience, the importance of protecting your children and kin and sacrificing yourself in the process is obvious. Not wanting to be “cared” for by siblings or children continues this position of self-sacrifice, where her needs are subsumed under the larger goal of looking out for the needs (e.g. career, health, family life) of those around her. Thus, for many women, recognizing and acknowledging their own needs and seeking assistance from others to meet those needs is contrary to her own life view and her perceptions of what her family needs from her. The logical and patterned step for her is to continue her position of caregiving through not “inconveniencing” those close to her. For her, the decision to forgo in-home family care is another way to continue to "care for her own,” to provide for them and to protect them. By “choosing” out of home placement and making their wishes known, these caregivers also are expanding the nature and definition of what it means to care and enabling those future caregivers to "care for their own” in ways that might not have been approved of by previous generations. 


\section{Demographic and Social Changes Affecting the Ethic of Care}

Demographic and social changes that are occurring throughout the United States and are affecting each cultural group to a significant degree also seem to be a factor in influencing caregivers’ choices about future care. The cultural lag, described by Groger and Mayberry (2001), in which traditional values that African Americans hold about in-home care are often at odds with contemporary families’ resources to provide such care and introduces a potential struggle and challenge for families to reconcile their beliefs and behaviors. For this particular sub-group of African-American caregivers, one way for them to assist the next generation in reconciling the ideal and reality is to take the decision out of their hands.

Research describes the growing demographic changes in family life in the U.S. including increased life expectancy, smaller family size, and increased geographic dispersion of families. The longer life expectancy has the potential to increase the lifetime risk of disability and need for care while at the same time there are less available caregivers on average due to smaller family size and greater geographic dispersion among families (Groger \& Mayberry, 2001; Zarit \& Eggebeen, 1995). When these demographic factors are combined with broader social forces of increased consumerism and individuality and decreased family and community connection (Etzioni, 1993; Putnam, 2000), such forces are bound to influence institutions, families, and the meaning of care. These broad social forces can be seen in the caregivers' narratives about caregiving being burdensome and acknowledging their children’s "separate lives."

\section{Caregiving as burdensome}

The strong sense of not wanting to burden others when they are no longer able to care for themselves carries with it an implicit message that caregiving is burdensome. In many ways, the stories and testimonials of the participants confirm this belief. Perceptions of caregiving as 
burdensome have implications for both the experience of caregiving and for those contemplating taking on that role. Liu (2000) argues that seeing in-home care as a burden and a sacrifice that is not fair to families is based on a Western model of care embedded in individualism. This view of caregiving as burdensome stands in contrast to the traditional view of seeing it as a normal part of the family life cycle-a common practice and an expected norm. In general, the more caregiving is separated from an expected or natural part of life, the more likely caregiving will be seen as a task of heroic proportions done by the few.

\section{Separate Lives}

Young people need to get on and live their own lives. [Rose]

I would tell them [her kids] that they have their own lives. [Margaret]

I wouldn't want to be a burden on them; I mean these are young people that have their own lives. [Yvonne]

These and other quotes like them highlight many of the participants' understanding of the nature of family relationships, that the lives of their children are in part separate and independent of their own lives. Traditional cultural values in the African American community place the importance of the group or "collective” above that of the individual. The needs of the individual are usually couched in terms of what is good for the group, and lives are seen as interconnected through mutual duties and responsibilities (Billingsley, 1992). Given the great heterogeneity existing among African American families and the rapid changes that have taken place in society over the last half-century, it is impossible to determine the extent to which this traditional ethic was or still is descriptive of African American families. The reality as it exists for this group of caregivers is that they have set limits around traditional values of the collective, at least when it comes to being the object of someone else’s duty, responsibility, or sacrifice. 


\section{Implications}

The current study and previous studies (e.g. Groger \& Mayberry, 2001) find that the experience of being a caregiver helps to shape and mold expectations for one’s own late life care. These studies show that age and experience tend to underscore the realities of what it means to provide in-home care to aging family members. For caregivers, the expectation to care for one's own is not a theoretical ideal, but a lived experience that is often hard to fulfill. For many, one way to re-envision what it means to take care of your own is to have lived the struggle of trying to balance the ideal with reality. But, for some, the issue is not fully resolved and they struggle with guilt for not having “done enough” or for having let their loved one, their family, or their community down.

It is important for pastors, educators, grief counselors, pastoral counselors, and family therapists to understand the tension that many families can face and to recognize the ambivalence that can emerge in the decision to become a caregiver, or in the decision to make an out of home placement. They are uniquely situated to assist people as they grapple with what it means to “care,” how best to provide care, and how to deal with the potential struggles that individuals and families can have in making caregiving decisions. The broader meaning of what it means to "care for your own” may be in the process of being re-shaped and re-cast as more and more individuals and families struggle with the competing demands of elder care and the available resources in contemporary family life to provide such care. Caring for one’s own, and whether it applies to only those families who are taking care of the body as well as the soul, or whether families can also be seen as doing this who are not involved in the "body work" but who are nurturing the mind and the spirit is a question for the larger community to grapple with in their churches, community centers, places of employment, and homes. 


\section{Limitations \& Future Directions}

As with any study of this size and scope, several factors limit the ability to generalize the findings. First, the small sample size and the fact that it was a convenience sample precludes us from making broad statements about caregivers and their future plans within a very diverse African American community. Second, the sample consisted of caregivers, both male and female, at different stages in the life cycle, caring for a range of family members who had a diverse set of medical issues. It may be that specific types of caregiver experiences have different affects on caregivers' future preferences for their own late life care. Due to sample size and diversity within the sample, we were not able to answer this question. Finally, we only have the stated future preference of caregivers, most of whom at this time are in good health and many who are years away from needing supportive care. Their preferences might change as they are confronted with their own care needs, or their family and larger social network might step in to assist despite their protestations.

Future studies focusing on families who have made a decision for out of home placement and the nature of the care that they give would enhance our understanding of the meaning of care. In addition, more research needs to be conducted on how the experience of being a caregiver shapes one’s own future care desires. Research designs that incorporate prospective analyses of attitudes and experiences and are longitudinal in nature will do much to increase our understanding of the caregiving experience. Future studies could also examine how the type of caregiver (Dilworth-Anderson's typology) and the nature of the illness of the care recipient affects what it means to care for one’s own and subsequent decision making. Finally, a comparison of caregivers who state a continued preference for in-home care versus those who prefer out-of-home placement with respect to their caregiving experiences, later life care 
expectations, and availability of potential caregivers for them would help us to better understand the influences that affect later life care decision making.

In conclusion, this study offers an initial investigation into why caregivers report their preference or openness to out of home placement rather than in-home family care. It provides a glimpse of the struggle that some individuals undergo in making decisions about how to "care for one's own" and in trying to reconcile strong expectations about what it means to care in a context where providing in-home care is difficult, or not an option. 


\section{References}

Bazeley, P., \& Richards, L. (2000). The NVivo qualitative project book. London: Sage.

Billingsley, A. (1992). Climbing Jacob’s ladder: The enduring legacy of AfricanAmerican families. New York: Simon \& Schuster.

Brabeck, M. M. (Ed.). (1989). Who cares?: Theory, research, and educational implications of the ethic of care. New York: Praeger.

Brody, E. M., Johnsen, P. T., \& Fulcomer, M. C. (1984). What should adult children do for elderly parents? Opinions and preferences of three generations of women. Journal of Gerontology, 39, 736-746.

Brody, E. M., Johnsen, P. T., Fulcomer, M. C., \& Lang, A. M. (1983). Women’s changing roles and help to elderly parents: Attitudes of three generations of women. Journal of Gerontology, 38, 597-607.

Bryant, S., \& Rakowski, W. (1992). Predictors of mortality among elderly African Americans. Research on Aging, 14, 50-67,

Crawley, L., Payne, R., Bolden, J., Payne, T., Washington, P., \& Williams, S. (2002). Palliative and end of life care in the African American community. Journal of the American Medical Association, 284, 2518-2521.

Creswell, J. W. (1994). Research design: Qualitative and quantitative approaches. Thousand Oaks, CA: Sage.

Dilworth-Anderson, P. (1992). Extended kin networks in black families. Generations: Journal of the American Society on Aging, 16, 29-32.

Dilworth-Anderson, P., Williams, S. W., \& Cooper, T. (1999). Family caregiving to 
elderly African Americans: Caregiver types and structure. Journal of Gerontology: Social Sciences, 54B, S237-S241.

Dyson, L. (1997). An ethic of caring: Conceptual and practical issues. Nursing Inquiry, 4, 196210.

Etzioni, A. (1993). The spirit of community: The reinvention of American society. New York: Simon \& Schuster.

Gilligan, C. (1982). In a different voice: Psychological theory and women’s development. Cambridge: Harvard University Press.

Greene, V. L. \& Ondrich, J. I. (1990). Risk factors for nursing home admissions and exits: A discrete time hazard function approach. Journal of Gerontology: Social Sciences, 45, S250-S258.

Groger, L. \& Mayberry, P. S. (2001). Caring too much?: Cultural lag in African Americans’ perceptions of filial responsibilities. Journal of Cross Cultural Gerontology, 16, 21-39.

Hill, R. B. (1972). The strengths of black families. New York: Emerson Hall.

Hill, R. B. (1999). The strengths of African American families: Twenty-five years later. Lanham, Maryland: University Press.

Hill, S. A. (1997). Ethnicity and the ethic of caring in African American families. Journal of Personal and Interpersonal Loss, 2, 109-128.

Kramer, B. J. (1997). Gain in the caregiving experience: Where are we? What next? Gerontologist, 37, 218-232.

Ladner, J. A. (1998). The ties that bind: Timeless values for African American families. New York: Wiley. 
Lofland, J., \& Lofland, L. H. (1995). Analyzing social settings: A guide to qualitative observation and analysis ( $3^{\text {rd }}$ Ed.). Belmont, CA: Wadsworth.

Liu, W. T. (2000). Values and caregiving burden: The significance of filial piety in elder care. In W. T. Liu and H. Kendig (Eds.) Who should care for the elderly? An East-West value divide (pp. 183-199). Singapore: Singapore University Press.

Maxwell, J. A. (1996). Qualitative research design: An integrative approach. Thousand Oaks, CA: Sage.

McAdoo, H. P. (1998). African-American families: Strengths and realities. In H. I. McCubbin, E. A. Thompson, A. I. Thompson, \& J. A. Futrell (Eds.), Resiliency in African-American families (pp. 17-30). Thousand Oaks, CA: Sage.

McFall, S., \& Miller, B. H. (1992). Caregiver burden and nursing home admission of frail elderly persons. Journal of Gerontology: Social Sciences, 47, S73-S79.

Pinquart, M., \& Sorensen, S. (2003). Differences between caregivers and noncaregivers in psychological health and physical health: A meta-analysis. Psychology and Aging, 18, 250-267.

Putnam, R. D. (2000). Bowling alone: The collapse and revival of American community. New York: Simon \& Schuster.

QSR International. (2002). Using NVivo for qualitative research. Melbourne, Australia: Author. Romero, R. E. (2000). The icon of the strong black woman: The paradox of strength. In L. C. Jackson \& B. Greene (Eds.), Psychotherapy with African American women: Innovations in psychodynamic perspectives and practice (pp. 225-238). New York: Guilford.

Schoenberg, N. E., \& Coward, R. T. (1997). Attitudes about entering a nursing home: 
Comparisons of older rural and urban African American women. Journal of Aging Studies, 11, 27-47.

Skoe, E. E. (1998). The ethic of care: Issues in moral development. In E. E. Skoe \& A. L. Von der Lippe (Eds.), Personality development in adolescence: A cross national and life span perspective (pp. 143-171). Florence, KY: Taylor \& Frances/Routledge.

Smith, D. B. (1991). Population ecology and the racial integration of hospitals and nursing homes in the United States. The Millbank Quarterly, 68, 561-597.

Steinbach, U. (1992). Social networks, institutionalization, and mortality among elderly people in the United States. Journal of Gerontology: Social Sciences, 47, S183-S190.

Sudha, S., \& Mutran, E. J. (1999). Ethnicity and eldercare: Comparisons of attitudes toward adult care homes and care by families. Research on Aging, 21, 570-594.

Taylor, R. (1998). The ethic of care versus the ethic of justice: An economic analysis. Journal of Socio-Economics, 27, 479-493.

Tesch, R. (1990). Qualitative research: Analysis types and software tools. New York: Falmer.

Tronto, J. C. (2001). An ethic of care. In M. B. Holstein \& P. B. Mitzen (Eds.), Ethics in community-based elder care (pp. 60-68). New York: Springer.

Turner, W. L., Wallace, B. R., Anderson, J. R., \& Bird, C. (2004). The last mile of the way: Understanding caregiving in African American families at the end of life. Journal of Marital and Family Therapy, 30, 427-438.

Waters, C. M. (2001). Understanding and supporting African Americans’ perspectives of end of life care planning and decision making. Qualitative Health Research, 11, 385-398.

Wimberly, A. S. (Ed.). (1997). Honoring African American elders: A ministry in the soul 
community. San Francisco: Jossey-Bass.

Wolinsky, F. D., Callahan, C. M., Fitzgerald, J. F., \& Johnson, R. J. (1992). The risk of nursing home placement and subsequent death among older adults. Journal of Gerontology: Social Sciences, 47, S173-S182.

Wykle, M., \& Kaskel, B. (1991). Increasing the longevity of minority older adults through improved health status. In Minority elders: Longevity, economics, and health (pp. 32-39). Washington, DC: Gerontological Society of America.

Young, R. F., Kosloski, K., \& Montgomery, R. J. (1998). Psychosocial factors in institutionalization of Alzheimer's patients. Journal of Clinical Geropsychology, 4, 241251.

Zarit, S. H., \& Eggebeen, D. J. (1995). Parent-child relationships in adulthood and old age. In M. H. Bornstein (Ed.), Handbook of parenting: Vol. 1, Children and parenting (pp. 119-140). Mahwah, NJ: Erlbaum. 